\title{
Psychological characteristics of patients with the irritable bowel syndrome
}

\author{
R. L. PALmer \\ M.B., B.S., M.R.C.Psych., D.P.M. \\ E. STONEHILl \\ A. H. CRISP* \\ M.D., M.R.C.Psych., D.P.M. \\ SHEILA L. WALLER \\ M.D., F.R.C.P.(E.), M.R.C.P., F.R.C.Psych., D.P.M. \\ B.Sc., M.B., B.S., M.R.C.P. \\ J. J. MISIEWICZ \\ B.Sc., M.B., B.S., M.R.C.P.(E.) \\ Academic Department of Psychiatry, St George's Hospital Medical School, London, S.W.17 and \\ Medical Research Council Gastroenterology Unit, Central Middlesex Hospital, London, N.W.10
}

\section{Summary}

The Eysenck Personality Inventory, the Middlesex Hospital questionnaire, and forearm blood-flow were used to measure aspects of psychological status in forty-one patients with the irritable bowel syndrome, who were compared in this respect with twenty-five matched psychoneurotic subjects and with a general population. The results show a positive association between psychoneurotic disorder and the irritable bowel syndrome.

\section{Introduction}

The cause of the irritable bowel syndrome (IBS) is unknown but emotional stress has been implicated as one possible factor. Some authors have proposed that the disorder is part of a more organized psychiatric illness, usually depressive in nature (Heffernon and Lippincott, 1966; Dorfman, 1967). This latter view has also recently been advanced by Hislop (1971). His patients with the irritable bowel syndrome reported symproms such as depression and insomnia significantly more often than a control population, and he also found a higher incidence of marital discord in his patient group. The disorder is said to respond well to a variety of psychiatric treatments such as relaxation training (Cohen and Reed, 1968) and phenothiazine and tricyclic drugs (Hislop, 1971). However, these drugs also directly affect bowel function, and it is conceivable that the same may be true of relaxation.

In the present study we have measured aspects of personality, psychoneurotic characteristics and forearm blood-flow in patients with the IBS and compared them with a matched group of patients suffering from psychoneurotic disorders (PD) and with previously studied control populations.

\footnotetext{
* Requests for reprints: Professor A. H. Crisp, Academic Department of Psychiatry, St George's Hospital Medical School, London, S.W.17.
}

\section{Patients and methods}

Patients with the IBS comprised forty-one of fifty persons previously reported as suffering from this disorder (Waller and Misiewicz, 1969). Of the remaining nine, one died of myocardial infarction, one went abroad, one could not come to the clinic for domestic reasons, and the other six patients failed to attend.

Patients with psychoneurotic disorders comprised twenty-five outpatients matched individually withe the IBS patients for sex, age (within 3 years for 30 . years or less, within 5 years for 31 years or more), social class, marital status and race. The diagnosis of psychoneurotic disorder was made by a consultant psychiatrist. Patients with neurotic depression, anxiety phobic state, obsessional illness, hysterical disorder, or a combination of these, were included.

Detailed information concerning the length of history, bowel habit and laxative taking was systematically collected from all the patients by the clinicians concerned, with the aid of a standard form. The severity of symptoms at the time of the interview was graded $(0-4)$, both by the patient and by the doctor. Each patient then completed the Eysenck Personality Inventory (EPI) Form A (Eysenck and Eysenck, 1964) and the Middlesex Hospital questionnaire (MHQ) (Crown and Crisp, 1966) administered in random order. The EPI is a measure of personality providing scores on two dimensions termed neuroticism and extroversion/introversion. A great deal of normative and other data are available on this test. The MHQ is a brief standardized selfrating inventory of psychoneurotic symptoms providing scores $(0-16)$ on six scales termed anxiety, phobic, obsessional, somatic, depression, hysteria.

The results of the EPI in the two clinical groups studied were compared with the published results for a normal population. The results of the MHQ in the male patients were compared with a pooled sample 
of 1969 men from previous studies (Crisp and Priest, 1971; Crown, Duncan and Howell, 1969; Crisp and Storey, 1972), whilst results of the MHQ in the females were similarly compared with a pooled sample of 505 women (Crisp and Priest, 1971; Crown et al., 1969; Crisp and Stonehill, 1969). The mean age of these control groups fell within 2 years of the study groups.

The MHQ scores in the IBS and PD patients were further compared with a sample of the general population comprising 1487 persons and adjusted to approximately the same sex ratio (two females : one male) (Crown and Crisp, 1966; Crisp and Priest, 1971; Crown et al., 1969; Crisp and Storey, 1972; Crisp and Stonehill, 1971; Liakos and Crisp, 1971). The average age of this control group was 10 years less than that of the IBS patients. Significance of differences in the questionnaire scores between the study and control groups were calculated with Student's ' $t$ ' test.

Letters were sent to the forty-one patients with IBS and of those who replied, sixteen agreed to attend for forearm blood-flow examination. This procedure was that described by Kelly (1966) and Kelly and Walter (1968); the results being expressed as millilitres of blood-flow $/ 100 \mathrm{ml}$ forearm tissue/min. The basal forearm blood-flow is a characteristic found to discriminate between groups of normal and psychiatric subjects, and also between groups of subjects with different psychiatric disorders. It is thought of as a measure of anxiety.

\section{Results}

There was no correlation between chronicity of the IBS and personality or psychoneurotic scores. No relationship was found between the state of the IBS and the total MHQ scores at the time that the questionnaire was filled in.

\section{Comparison of matched IBS and PD patients}

The sample of twenty-five IBS patients (fifteen women, ten men) who were matched with the psychoneurotics, did not differ significantly from the whole IBS group (forty-one patients) with regard to sex ratio, age, EPI or MHQ scores: they were therefore held to be representative of the IBS population.

The number of laxative takers, length of symptoms and severity of illness at the time of the test were similar in twenty-five IBS and the twenty-five PD patients. On the other hand, there were clear differences in bowel habit and characteristics of the stool between the irritable bowel and the neurotic patients (Table 1).

Results obtained with the EPI questionnaire are displayed in Table 2. The mean score for neuroticism in the twenty-five IBS patients was significantly lower than in matched patients with PD, but the two groups had a similar degree of extroversion. When these data were examined by sex, the difference remained significant only for females $(P<0.02)$.

Average scores obtained with the MHQ questionnaire are in Fig. 1. Again IBS and neurotic patients differed significantly with respect to all six

TABLE 1. Bowel habit at time of study in the matched IBS and PD patients

\begin{tabular}{|c|c|c|c|c|c|c|c|c|}
\hline & \multicolumn{3}{|c|}{ Frequency } & \multicolumn{3}{|c|}{ Abnormal consistency* } & \multirow{2}{*}{$\begin{array}{l}\text { Mucus } \\
\text { present }\end{array}$} & \multirow{2}{*}{$\begin{array}{l}\text { Occasional } \\
\text { blood }\end{array}$} \\
\hline & $>1 /$ day & $1 /$ day & $<1 /$ day & Hard & Loose & 'Rabbitty' & & \\
\hline $\begin{array}{l}\text { IBS } \\
\text { PD }\end{array}$ & $\begin{array}{r}12 \\
0\end{array}$ & $\begin{array}{r}7 \\
19\end{array}$ & $\begin{array}{l}6 \\
6\end{array}$ & $\begin{array}{l}9 \\
7\end{array}$ & $\begin{array}{r}14 \\
1\end{array}$ & $\begin{array}{r}14 \\
1\end{array}$ & $\begin{array}{l}8 \\
1\end{array}$ & $\begin{array}{l}2 \\
2\end{array}$ \\
\hline
\end{tabular}

* Most patients with the IBS had >1 type of stool.

TABLE 2. EPI data Mean \pm S.S. Results for normal population taken from Eysenck and Eysenck

\begin{tabular}{lcccc}
\hline & $\mathrm{n}$ & $\begin{array}{c}\text { Extroversion } \\
\text { score }\end{array}$ & $\begin{array}{c}\text { Neuroticism } \\
\text { score }\end{array}$ & Lie score \\
\hline Sub-group of IBS & 25 & $9.36 \pm 3 \cdot 12$ & $11.64 \pm 5.67$ & $3.24 \pm 1.76$ \\
Matched PD & 25 & $10.36 \pm 4.30$ & $15.89 \pm 4.85$ & $2.88 \pm 1.96$ \\
IBS vs PD & & n.s. & $P<0.01$ & n.s. \\
IBS & 41 & $10.66 \pm 3.62$ & $11.98 \pm 5.62$ & $\begin{array}{c}4.02 \pm 1.96 \\
\text { Normal population }\end{array}$ \\
IBS vs Normal & 2000 & $12.07 \pm 4.37$ & $9.06 \pm 4.78$ & $2.26 \pm 1.57$ \\
& & $P<0.001$ & $P<0.001$ & $P<0.001$ \\
\hline
\end{tabular}


psychoneurotic categories, but when examined by sex, the differences remained significant only for females, although the same trend existed in the smaller number of male subjects.

\section{Comparison of IBS patients with a general popula- tion}

The forty-one patients with IBS were significantly more neurotic and less extroverted than a sample of the normal population, as judged by EPI scores (Table 2), and these differences remained highly significant when the results were analysed for men and women separately.

In the MHQ the IBS patients also recorded significantly higher scores than a general population for all psychoneurotic categories except hysteria (Fig. 1). Examination of MHQ data by sex showed that both men and women were more anxious than the general population, whereas scores in the other dimensions were variable (Table 3 ). There was a consistent tendency for IBS patients to score more highly on all scales, although this only sometimes reached statistically significant levels.

\section{Forearm blood-flow}

The sixteen patients with IBS in whom basal forearm blood-flow was measured did not differ from the whole IBS population with respect of age, sex distribution or the EPI and MHQ scores.

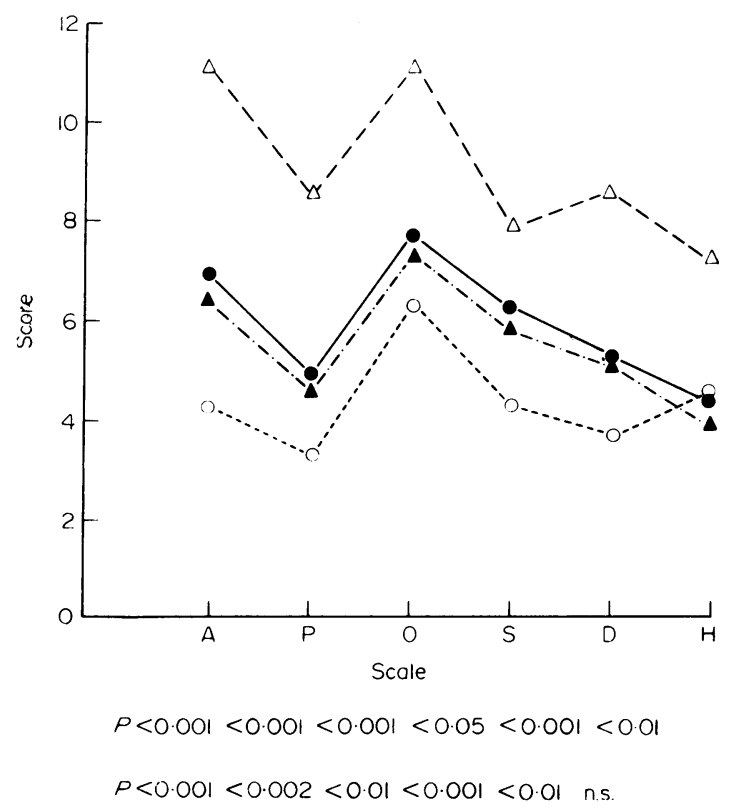

FIG. 1. MHQ scores for men and women. O, general population; $O$, forty-one IBS patients; $\Delta$, twenty-five IBS patients matched with twenty-five PD patients; $\triangle$, twenty-five PD patients. Significant differences between groups are indicated below each psychoneurotic category. $A=$ free floating anxiety; $P=$ phobic anxiety; $\mathrm{O}=$ obsessional traits; $\mathrm{S}=$ somatic symptoms; $\mathrm{D}=$ depressive; and $\mathrm{H}=$ hysterical traits.

TABLE 3. MHQ scores for men and women separately

\begin{tabular}{|c|c|c|c|c|c|c|c|c|}
\hline & \multirow[b]{2}{*}{$\mathrm{n}$} & \multirow[b]{2}{*}{ Mean age } & \multicolumn{6}{|c|}{ MHQ scores mean + s.d. } \\
\hline & & & A & $\mathbf{P}$ & $\mathbf{O}$ & $\mathbf{S}$ & D & $\mathbf{H}$ \\
\hline \multicolumn{9}{|l|}{ Males } \\
\hline IBS & 16 & $40 \cdot 8$ & $6 \cdot 3 \pm 4 \cdot 2$ & $3 \cdot 4 \pm 3 \cdot 4$ & $7 \cdot 8 \pm 3 \cdot 4$ & $5 \cdot 8 \pm 3 \cdot 0$ & $3.9 \pm 2.9$ & $4 \cdot 7+4 \cdot 3$ \\
\hline $\begin{array}{l}\text { General population } \\
\text { IBS vs general population }\end{array}$ & 1969 & $41 \cdot 8$ & $3 \cdot 3 \pm 2 \cdot 8$ & $2 \cdot 4 \pm 2 \cdot 1$ & $6 \cdot 4 \pm 3 \cdot 1$ & $3 \cdot 8 \pm 3 \cdot 0$ & $2 \cdot 8 \pm 2 \cdot 5$ & $3 \cdot 5+3 \cdot 1$ \\
\hline $\begin{array}{l}\text { IBS vs general population } \\
\text { Females }\end{array}$ & & n.s. & $P<0.01$ & n.s. & n.s. & $P<0.01$ & n.s. & n.s. \\
\hline IBS & 25 & $46 \cdot 2$ & $7 \cdot 3 \pm 4 \cdot 3$ & $6 \cdot 0 \pm 2 \cdot 9$ & $7 \cdot 6 \pm 2 \cdot 9$ & $6 \cdot 6 \pm 3 \cdot 7$ & $5 \cdot 9 \pm 3 \cdot 1$ & $4 \cdot 2+2 \cdot 9$ \\
\hline General population & 505 & $48 \cdot 7$ & $5 \cdot 3+3 \cdot 5$ & $4 \cdot 5+2 \cdot 8$ & $7 \cdot 1 \pm 2 \cdot 9$ & $5 \cdot 3 \pm 3 \cdot 3$ & $4 \cdot 2 \pm 2 \cdot 5$ & $\mathbf{3} \cdot \mathbf{1} \pm \mathbf{2} \cdot \mathbf{7}$ \\
\hline IBS vs general population & & n.s. & $P<0.05$ & $P<0.02$ & n.s. & n.s. & $P<0.01$ & n.s. \\
\hline
\end{tabular}

TABLE 4. Basal forearm blood-flows $(\mathrm{ml} / 100 \mathrm{ml} / \mathrm{min})$ in IBS patients. All other data from Kelly and Walter (1968)

\begin{tabular}{lrcc}
\hline & $\mathrm{n}$ & $\begin{array}{c}\text { Mean } \\
\text { s.d. }\end{array}$ & $\begin{array}{c}\text { Compared } \\
\text { with IBS }\end{array}$ \\
\hline IBS & 16 & $3.14 \pm 1.21$ & \\
Normal controls & 60 & $2.21 \pm 1.05$ & $P<0.01$ \\
Chronic anxiety & 41 & $4.45 \pm 1.33$ & $P<0.001$ \\
Agitated depression & 15 & $3.54 \pm 1.09$ & n.s. \\
Schizophrenia & 20 & $3.31 \pm 1.25$ & n.s. \\
Obsessional neurosis & 20 & $2.65 \pm 0.9$ & n.s. \\
Phobic state & 32 & $2.26 \pm 0.95$ & $P<0.02$ \\
Hysteria & 9 & $2.20 \pm 1.02$ & $P<0.05$ \\
Non-agitated depression & 43 & $2 \cdot 13 \pm 0.62$ & $P<0.02$ \\
Personality disorder & 15 & $1.90 \pm 0.55$ & $P<0.01$ \\
Depersonalization & 8 & $1.84 \pm 1.01$ & $P<0.01$ \\
\hline
\end{tabular}


The average basal forearm blood-flow in the group was significantly higher $(P<0.01)$ than in the normal population studied by Kelly and Walter (1968). It was significantly lower than the forearm blood-flow observed in patients with chronic anxiety states, similar to the flow in patients with agitated depression and schizophrenia, and higher than that found in most other psychiatric groups studied by the same authors (Table 4).

\section{Discussion}

Results of the present investigation suggest that patients suffering from the IBS have a moderate degree of psychoneurotic disorder in the form both of a neurotic personality structure and the presence of psychoneurotic symptoms. In general both the EPI and the MHQ mean scores of patients with IBS fell between the mean scores of control subjects and the matched psychoneurotic patients and were significantly different from both. The present results also indicate that neurotic disorder may be a more pervasive characteristic of the IBS than the bowel symptoms, being unrelated to the chronicity of the latter symptoms or their immediate intensity. Patients with IBS had higher forearm blood-flows than had been observed in most groups of psychiatric disorders with the exceptions of chronic anxiety, agitated depression and schizophrenia (Kelly and Walter, 1968), forms of psychiatric illness which in themselves are of ten associated with physical complaints.

This study has therefore shown a positive association between the IBS and neurotic personality and psychoneurotic disorder. Although patients with the syndrome reported the experience of less neurotic disorder than matched psychoneurotic subjects, the high basal forearm blood-flow rates suggest that they may be in a highly 'aroused' state. It remains difficult, however, to evaluate the significance of such characteristics in individual patients with the IBS. For instance severe neurotic disorders (e.g. as measured by the MHQ (Crisp and Priest, 1971)) have been found to be present in nearly $10 \%$ of the general population. Whether or not such individuals seek help from doctors is determined by complex factors, and if and when they do they may then complain of symptoms which may or may not be directly related to their neurotic disorder. Conversely, chronic physical disability can sometimes promote neurotic symptoms. The present observations give overall support to the proposition that personality and experiential factors are significant aspects of the irritable bowel syndrome, probably having important aetiological and therapeutic implications for many such patients.

\section{References}

COHEN, S.I. \& REED, J.L. (1968) The treatment of 'Nervous Diarrhoea' and other conditioned autonomic disorders by desensitization. British Journal of Psychiatry, 114, 1275.

CrisP, A.H. \& Priest, R.G. (1971) Psychoneurotic profiles in middle-age. British Journal of Psychiatry, 119, 385.

Crisp, A.H. \& Stonehill, E. (1969) Aspects of the psychological status of patients treated with cardiac pacemakers. Postgraduate Medical Journal, 45, 423.

Crisp, A.H. \& Storey, P.B. Personal communication.

Crown, S. \& CRISP, A.H. (1966) A short clinical diagnostic self-rating scale for psychoneurotic patients. The Middlesex Hospital Questionnaire (M.H.Q.). British Journal of Psychiatry, 112, 917.

Crown, S., Duncan, K.P. \& Howell, R.W. (1969) Further evaluation of the Middlesex Hospital Questionnaire (M.H.Q.). British Journal of Psychiatry, 116, 33.

DoRfMaN, W. (1967) Somatic components of depression. Psychosomatics, 8, 4.

EYSENCK, H.J. \& EYSENCK, S.B.G. (1964) Manual of the Eysenck Personality Inventory. University of London Press.

HefFernon, E.W. \& LipPincotT, R.C. (1966) The gastrointestinal response to stress (the irritable colon). Medical Clinics of North America, 50, 591.

HisLOP, I.G. (1971) Psychological significance of the irritable colon syndrome. Gut, 12, 452.

KELLY, D.H.W. (1966) Measurement of anxiety by fore-arm blood flow. British Journal of Psychiatry, 112, 789.

Kelly, D.H.W. \& WALTER, C.J.S. (1968) The relationship between clinical diagnosis and anxiety assessed by forearm blood flow and other measurements. British Journal of Psychiatry, 114, 611.

Liakos, A. \& Crisp, A.H. (1971) Pupil size in psychoneurotic patients. Psychotherapy and Psychosomatics, 19, 104.

WAller, S.L. \& Misiewicz, J.J. (1969) Prognosis in the irritable bowel syndrome. Lancet, ii, 753. 